\title{
Um novo regime da morte na $\mathrm{TV}^{1}$
}

\section{Cristina Teixeira Vieira de Melo}

\section{Resumo}

Estamos vivendo uma mudança cultural em que novas formas de morrer despontam para os sujeitos. 0s Cuidados Paliativos (CP) figuram como um desses novos regimes da morte. Sustentamos que embora se coloquem contra uma biopolítica do investimento na vida a qualquer custo, os CP estão em consonância com a governamentalidade contemporânea, na qual impera uma otimização da vida. 0 ethos do moribundo é o mesmo do indivíduo neoliberal, levado a pensar a si como alguém que modela ativamente 0 curso de sua vida (e de sua morte) através de atos de escolha. Para mostrar como isso se dá, elegemos como objeto de análise uma série de TV americana que tem por base os preceitos dos CP chamada Time of death (2013).

\section{Palavras-Chave}

Time of death. Cuidados paliativos. Biopolítica. Governamentalidade. Ethos neoliberal.

\section{Cristina Teixeira Vieira de Melo | \\ cristinateixeiravm@gmail.com}

Doutora em Linguística pela Universidade Estadual de Campinas UNICAMP, Brasil. Realiza pós-doutorado no Programa de PósGraduação em Comunicação e Cultura da Universidade Federal do Rio de Janeiro - UFRJ, Brasil. Professora do Programa de Pós-Graduação em Comunicação Social da Universidade Federal de Pernambuco - UFPE, Brasil.

\section{Perspectivas da morte}

0 contemporâneo abriga diferentes discursos e práticas sobre o morrer e a morte que mantém entre si relações de aliança ou de concorrência e se desenvolvem em torno de debates éticos que põem em questão a autonomia do sujeito. Esses discursos e práticas se aproximam e se distanciam à medida que defendem ou repudiam procedimentos que visam à manutenção do processo natural da morte, sua antecipação ou seu prolongamento. Por exemplo, a eutanásia e 0 suicídio assistido buscam abreviar a vida de um paciente acometido de doença grave $\mathrm{e}$ incurável a fim de evitar-lhe mais sofrimento. Ambos estão em relação de oposição à distanásia, procedimento que prolonga por meios artificiais o processo de morte de um doente terminal, mantendo-o clinicamente vivo, mas alienado de si. Já a ortotanásia contribui para que 0 processo da morte siga 0 seu curso natural ao suspender tratamentos invasivos e artificiais que prolongam a vida do paciente, mas não curam nem melhoram a enfermidade. Tal procedimento se associa à implementação dos Cuidados Paliativos 
(CP), assistência promovida por uma equipe multidisciplinar a um paciente acometido de doenças graves e incuráveis - e também a sua família, auxiliando no controle de sintomas físicos, psicológicos, sociais e espirituais com o objetivo melhorar a qualidade de vida de todos.

Nesta disputa pelo "jeito certo de morrer", os discursos e as condutas que visam à manutenção da integridade do sujeito, sua maior autonomia, menor sofrimento, melhor qualidade de vida e uma morte digna estão ganhando força. Assim sendo, a distanásia, comumente praticada pela medicina tradicional nas unidades de terapia intensiva (UTIs) dos hospitais, embora se mantenha como 0 modo predominante de morrer no contemporâneo, tem sido bastante questionada, pois, ao subordinar o paciente aos saberes e poderes médicos, retira dele a possibilidade de decidir quais procedimentos quer adotar, além de mantêlo isolado do convívio social.

Por sua vez, métodos como a eutanásia e 0 suicídio assistido, que objetivam apressar a morte de um paciente designado "fora de possibilidades terapêuticas" (FPT), ainda encontram muita resistência por parte da sociedade, pois, tanto na esfera secular quanto religiosa, predomina a ideia de que a vida humana tem um valor sagrado. Do ponto de vista jurídico, são poucos os países onde a eutanásia e/ou o suicídio assistido são legalizados.

No Brasil, ambos são considerados crime.

Nesse cenário, os CP desfrutam de vantagens na disputa sobre a melhor forma de morrer. Por um lado, como não almejam abreviar a vida do paciente, não enfrentam problemas para serem socialmente aceitos; por outro, contrapõemse explicitamente ao modelo considerado "desumano", "frio", "altamente tecnológico", "impessoal" e excessivamente "racionalizado e institucionalizado" de gestão da vida de pacientes terminais da medicina tradicional.

Menezes (2004) lembra que o projeto dos CP é ambicioso, pois, sua proposta de aceitação da morte busca um impacto social de grande amplitude. Para tanto, têm sido feitos investimentos na divulgação de seus ideários nos meios de comunicação de massa (revistas, jornais, cinema, televisão etc.), mídias sociais e veículos especializados de divulgação científica. Inúmeras são as publicações acadêmicas e os manuais técnicos abordando o tema. Uma rápida busca no google acadêmico com a expressão "cuidados paliativos" exibe o resultado de 51.200 ocorrências. Uma consulta na amazon.com.br indica 1.660 títulos disponíveis sobre 0 assunto, sejam eles de natureza técnica ou depoimentos de autoajuda². Os esforços para criação e 
desenvolvimento de entidades profissionais e formação de pessoal qualificado em CP também é grande. Não é à toa que os CP vêm ganhando espaço nos discursos institucionais e nas políticas de saúde no mundo todo.

No Brasil, em 1997, foi fundada a Associação Brasileira de Cuidados Paliativos (ABCP). Em 2005, foi a vez da Academia Nacional de Cuidados Paliativos (ANCP). Em 2009, o Conselho Federal de Medicina (CFM) incluiu, em seu novo Código de ética Médica, os CP como princípio fundamental e, em 2011, regulamentou-os como área de atuação médica. Desde 0 início dos anos 2000, foram adotadas pelo Ministério da Saúde uma série de medidas paliativistas visando os pacientes de doença grave.

A mídia brasileira também tem direcionado uma atenção especial aos CP. Enfim, trata-se de uma gama de dizeres e saberes emitidos por especialistas em seus campos de atuação que culminam por influenciar a opinião pública. Nesse artigo, interessa-nos pensar como 0 dispositivo midiático, ao abordar os $\mathrm{CP}$, tem posto em circulação um posicionamento frente ao processo de morrer cujo efeito é a produção de uma subjetivação típica da governamentalidade contemporânea, na qual impera uma "otimização da vida" (ROSE, 2013). 0 objeto de análise é a série Time of death (2013), produzida pelo canal norte-americano Showtime e veiculada no Brasil em 2015 pelo canal de TV por assinatura GNT. 0 objetivo principal é apontar de que forma, a nível do visível e do dizível, os ideários do discurso paliativista se materializam na série, ao mesmo tempo que certas manifestações do morrer são minimizadas, silenciadas ou interditadas.

\section{Poder médico-hospitalar}

Na sociedade atual, o saber médico e o hospital são referências centrais na gestão da morte. Em caso de doença grave, o médico costuma encaminhar o doente para o hospital, onde predomina uma medicalização completa do processo de morrer. Lá, todos os esforços são feitos para impedir a morte e prolongar a vida. No contexto médico-hospitalar a morte virou sinônimo de fracasso. Então, para evitá-la, lança-se mão de procedimentos diversos: reanimação, nutrição, hidratação e respiração artificiais, entre tantos outros. Os avanços técnicos-científicos foram acentuando a ideia de que, embora inevitável, a morte pode ser controlada, sendo possível 0 médico regular-lhe a duração. Hoje, a medicina pode permitir a um quase morto sobreviver por tempo indeterminado. Nesse contexto, é legítimo pensar no hospital como uma "instituição de sequestro" que atua sobre os corpos favorecendo a operacionalização da "biopolítica" (FOUCAULT, 1987, 1997).

A despeito de a instituição médico-hospitalar existir para curar o paciente e lhe proporcionar bem-estar, o saber/poder médico nunca deixa de funcionar a favor de sua própria racionalidade, impondo ao doente uma série de normas e regras 
para melhor gerir sua saúde, vida e morte. Ariés afirma que a medicina e 0 hospital fazem da produção médica "uma administração e uma empresa que obedece a regras estritas de método e disciplina" (2012, p.790). 0 crescente poder médico resultou num processo cada vez maior de desumanização, assujeitamento e objetificação do doente, especialmente aqueles designados em "estado terminal". 0 moribundo tem sua autonomia usurpada, é despossuído de voz, não há escuta para a expressão de seus sentimentos e desejos.

No hospital, a morte é "monitorizada, controlada, inconsciente, silenciada e escondida" (MENEZES, 2004, p. 33). Ela não deve interromper a rotina hospitalar, deve ser discreta. Se a morte sob efeito de sedativos pode ser considerada "bem-sucedida" do ponto de vista médico, nem sempre é tida como "boa" para 0 doente e seus familiares. 0 paciente morre assepticamente nas UTIs com recursos tecnológicos modernos e especializados, mas em total isolamento, longe da família e dos amigos.

David Sudnow (1967) nomeia "morte social" 0 processo anterior a morte biológica que ocorre quando o doente é tratado no tempo passado como se já estivesse morto. Nobert Elias (2001), por sua vez, aborda a "solidão dos moribundos" não somente como isolamento físico, mas como uma solidão em meio à comunidade, na qual aquele que está no fim da vida perde seu significado social. Elias utiliza a expressão "morte recalcada" para falar da incapacidade das pessoas de se aproximarem dos moribundos já que a iminência da morte dos outros relembraria a própria mortalidade. 0 sociólogo alemão afirma que durante 0 processo civilizador, as pessoas passaram a sentir "vergonha, repugnância e embaraço" diante da morte, sendo incapazes de demonstrar afeição e carinho a um moribundo, a quem restou o isolamento e a solidão. Assim, a morte foi banida para os bastidores da vida social.

\section{Cuidados Paliativos}

Em contraponto aos excessos da instituição médica surgiram, especialmente a partir da década de 1970, movimentos pelos direitos dos doentes. Estes movimentos buscaram romper com o regime da "morte moderna" acima descrita. "Do silêncio, ocultamento e negação passou-se à colocação da morte em discurso" (MENEZES, 2004, p.37). 0s CP inserem-se nesse contexto.

Esse tipo de cuidado se fortaleceu a partir do movimento hospice moderno, introduzido por Cicely Saunders, assistente social, enfermeira e médica, que, em 1967, fundou na Inglaterra o St. Christopher's Hospice. Posteriormente, a filosofia hospice se difundiu na França, nos Estados Unidos e no Canadá. Hoje, a incorporação dos CP nas políticas de saúde de vários países indica uma mudança cultural em que novos "dispositivos de saber e poder" (FOUCAULT, 1997, 2000) engendram novas formas de morrer.

Diferentemente dos profissionais de saúde que olham a morte de um paciente como um fracasso 
e investem no prolongamento da vida a qualquer preço, para aqueles que seguem os preceitos dos CP a morte é um evento natural e esperado diante de uma "doença ameaçadora da vida". 0 s paliativistas alertam os menos esclarecidos de que não se trata de uma opção quando "nada mais há para fazer", "uma não medicina", um "tratamento de segunda linha"; e sim de uma outra concepção da relação entre vida e morte em que a prioridade não é mais do que "salvar vidas, mas propiciar boas mortes" (MENEZES, 2004, p.12). No prefácio do livro "Cuidados Paliativos, conversas sobre a vida e a morte na saúde", Maria Júlia Kovács afirma: "se a morte é vista como ameaça, a vida perde 0 sentido, mas se é vista como a consciência da finitude e que 0 sentido da vida se baseia nessa consciência, não há como ser ignorada." (BIFULC0, 2016, p.16).

Os CP se contrapõem ao isolamento, silenciamento e a perda de identidade social do doente internado nas UTIs dos hospitais, propondo uma nova rede de práticas e de significados para o processo do morrer e da morte. Trata-se de um processo de desmedicalização e humanização da morte. A proposta é assistir o moribundo até os seus últimos momentos, assegurando-lhe "qualidade de vida" ao aliviar sua dor, restituir-lhe à presença da família e dos amigos, preserva-lhe a "identidade pessoal" e possibilitar-lhe a "maior autonomia possível", permitindo assim que ele tenha uma "morte digna", uma "boa morte".

0s CP buscam ajudar o paciente e sua família em todos os estágios da doença: negação e isolamento; raiva, barganha, depressão, aceitação (KÜBLERROSS, 2008). 0 objetivo é tratar não só o sofrimento físico, mas o psicossocial de ambos (doente e família), bem como a espiritualidade, considerada uma dimensão vital. Nos CP a ideia de espiritualidade transcende a religiosidade e deve abordar questões existenciais como as seguintes: Qual o sentido da vida? Qual foi o sentido de minha vida? Para onde irei depois da morte? Desta forma, os CP fazem com que, através da morte, os doentes "encontrem a sua própria verdade", dando sentido as suas vidas.

Com esse enfoque holístico, os CP veem o paciente não apenas como um ser biológico, mas antes de tudo biográfico. Menezes (2004) afirma que, segundo o ideário paliativista, para terminar "bem" a vida é preciso resolver questões em aberto, sejam elas de ordem material ou emocional. Os CP se colocam no lugar de valorização da família ao promover encontros e reencontros. Equipe médica, familiares e amigos são mobilizados para que os conflitos familiares e/ou problemas legais sejam resolvidos. Nesse contexto, são estimulados os atos de perdão (pedir perdão, ser perdoado, perdoar a um outro, perdoar a si mesmo). Ao solucionar as questões pendentes, mesmo parcialmente, 0 paciente

Em CP não se fala mais em "terminalidade”, mas em "doença que ameaça a vida".

0s grifos em aspas referem-se às expressões discursivas recorrentes no discurso dos paliativistas. 
sente-se livre de uma "vida obstinada" e com "autorização para partir".

Como objetiva "cuidar da pessoa como um todo", a assistência prestada pelos CP é multidisciplinar. Envolve médicos de várias especialidades, enfermeiro, assistente social, psicólogo, fisioterapeuta, terapeuta ocupacional, fonoaudiólogo, nutricionista, dentistas, entre outros profissionais. 0 lugar onde estes cuidados são prestados é preferencialmente a casa do paciente, pois assim ele "tem suas necessidades atendidas na medida de suas preferências, sem a necessidade de seguir a rigidez das regras e horários do hospital" (ANCP, 2012, p.90). Além disso, simbolicamente, a casa representa 0 "retorno ao ventre materno, local de aconchego, calor e proteção" (ANCP, 2012, p.90). Os CP também estão presentes em hospitais ou em instituições que oferecem a filosofia hospice. Em qualquer dos casos (casa, quarto de um hospital ou em um hospice) os ambientes devem manter a decoração e 0 estilo do paciente a fim de preservar sua individualidade, suas características pessoais.

Cabe à equipe médica discutir de forma franca com o paciente o prognóstico e os tratamentos, dando a ele e a sua família o suporte necessário para a tomada de decisões. 0 doente e sua família são estimulados a falar do seu sofrimento, contribuindo para a elaboração das experiências de adoecimento, processo de morte e luto. Assim, vive-se sistematicamente um "luto antecipatório"6, no qual as despedidas e a expressão de emoções ocupam lugar central.

0s CP dispensam uma atenção muito grande à construção da cena da morte. À imagem da "boa morte" associa-se a ideia da "morte pacífica". Nesse sentido, no momento final, o doente deveria se manter tranquilo. Segundo Menezes (2004, p.47), os CP têm como ideal um "final de vida digno e belo" para uma vida que deveria ter sido vivida como uma "obra harmoniosa e produtiva" e a pessoa que se vai deve deixar uma "marca singular" para seu círculo social. A busca desse aperfeiçoamento deve se mostrar, inclusive, na apresentação de um corpo cuidado, com boa aparência. Tudo isso caminha para uma estetização da morte. Especialmente nos EUA, é frequente 0 uso da chamada "necromaquiagem" a fim de melhorar a aparência do morto e preservar suas características.

\section{Contrapontos ao ideário paliativista}

0 cenário redentor da "boa morte" dos CP exacerba a aceitação e naturalização desse acontecimento. No entanto, algumas contradições surgem no meio desse discurso. Menezes (2004) lembra que até uma determinada etapa do tratamento, o paciente é estimulado a lutar contra a doença, não devendo 
"se entregar", mas quando é considerando um paciente FPT, deve aceitar pacificamente a vitória da enfermidade e começar a tomar decisões referentes ao tempo que lhe resta de vida.

Os críticos também apontam que os cinco estágios descritos por Kübler-Ross passaram a ser utilizados pelos paliativistas como um modelo prescritivo sobre a maneira como se deve morrer. A expressão das emoções, por sua vez, ao mesmo tempo que são estimuladas, são submetidas a um excesso de burocratização e normatização. Menezes (2004) assinala que em certos contextos, a raiva, a indignação, o choro mais intenso, os gritos, os gemidos podem ser objeto da intervenção de profissionais, para contenção.

Outra contradição: a tecnologia que engendra as condições de desenvolvimento de uma medicina desumana é a mesma que propicia a humanização do morrer, pois, os paliativistas necessitam dos recursos farmacológicos para controle dos sintomas dos pacientes. A "boa morte" depende de uma expertise técnica que produz uma normalização médica da morte. Portanto, "não se trata de uma libertação do aparato médico, mas sim de um refinamento e capilarização de suas formas de controle". (MENEZES, 2004, p.214)

Nos CP ainda são estimuladas práticas de confissão e de cultivo à interioridade. Na esteira de Foucault, Menezes lembra que "o dispositivo de poder é tanto
0 silêncio como 0 incitamento ao discurso, é tanto 0 ocultamento social, quanto o tornar público e visível" (2004, p.214). Assim, quanto mais o sujeito manifesta seus sentimentos, mais profunda e ampla se torna a vigilância e o controle sobre sua individualidade.

A configuração da morte dos CP está em consonância com a governamentalidade contemporânea, na qual, a partir de uma complexa mistura de política da vida e da morte, impera uma "otimização da vida" (ROSE, 2013). Na busca por "qualidade de vida", "dignidade", "autonomia" e "felicidade" para viver o tempo que lhe resta, aquele que está em vias de morrer, embora auxiliado pelos peritos do corpo e da alma, é responsável pelas escolhas que faz, incluindo as decisões de risco que toma. Enfim, é um "empreendedor de si", bem aos moldes do ethos neoliberal. Não é por acaso que 0 discurso paliativista se mescla ao de autoajuda. Nesse contexto, a administração das circunstâncias do morrer e o domínio de si mesmo colocam-se como uma espécie de compensação à impossibilidade de controlar o mundo, no caso, a morte iminente. Em função de tudo isso, os $\mathrm{CP}$ não deixam de ser, embora de uma maneira bem distinta da "morte moderna", uma "domesticação da morte", uma verdadeira "pedagogia do morrer".

\section{Time of death, uma breve descrição}

Time of death é uma série americana de seis episódios ${ }^{7}$ que registra os últimos dias de vida e 0 
exato momento da morte de oito doentes terminais:

Maria Lencioni, Michael John Muth, Lenore

Lefer, Cheyenne Bertiloni, Antoniette (Toni)

Yancey, Laura Kovarik, Morris Bradley e Nicolle

Kissee. Com exceção de Cheyenne, acometido de esclerose lateral amiotrófica (ELA), os demais lutam contra 0 câncer dos mais variados tipos.

A montagem é feita de forma alternada: cada episódio inicia narrando a história de uma personagem, depois mostra uma outra, na sequência volta para a primeira, e assim as histórias vão se sucedendo. Para marcar a passagem de uma história a outra sempre aparece na tela uma cartela como o nome da personagem que entrará em cena.

A história de Maria (48), vítima de câncer de mama em estágio IV e mãe de três filhos: Nicole (25), Andrew (14) e Julia (15) perpassa os seis episódios, enquanto as demais personagens aparecem apenas em um ${ }^{8} .0$ programa registra oito meses do tempo de vida de Maria. Já o período dedicado a acompanhar o agravamento da doença dos demais enfermos gira em torno de dois a três meses. Assim, a história de Maria vai ganhando protagonismo. Além disso, 0 tipo de registro imagético que se tem de Maria é bem mais diversificado. Afora as imagens feitas pela equipe do programa, sua filha Nicole filma sistematicamente a mãe e os irmãos. As imagens da câmera caseira de Nicole permitem ao espectador ter acesso a momentos de muita intimidade da família, incluindo brigas e desavenças. Esta característica contribui para classificar o programa como um reality show, embora ele se autodefina como "documentário". É bom lembrar que a série é uma realização da Magical Elves Production, responsável pelos aclamados Top Chef e Project Runway.

Atuando na frente e por trás das câmeras, Nicole tem bastante destaque na série. É a única pessoa fora do perfil "doentes terminais" que a equipe de filmagem acompanha regularmente. A série se inicia com Nicole ao telefone comunicando a morte de Maria a um serviço de emergência. Na sequência, a história retrocede oito meses. Maria aparece recebendo a notícia de que seu câncer piorou. A cena do telefonema é retomada no penúltimo episódio quando, através das imagens da câmera caseira de Nicole, presenciamos o momento em que ela encontra a mãe morta na cama.

Figura 1: Nicole encontra Maria morta na cama. Time of death (Showtime, 2013)

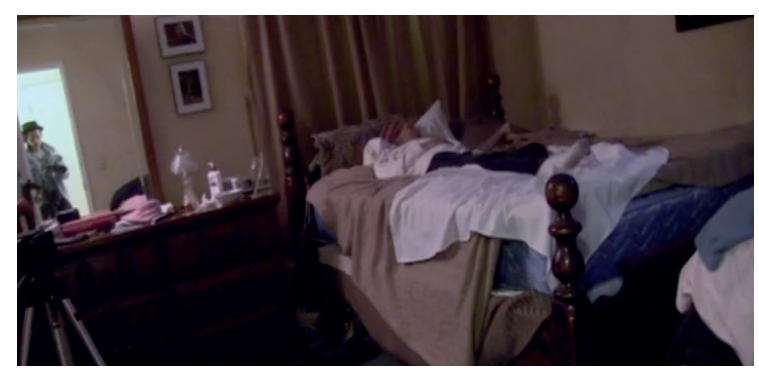


Os recuos e avanços no tempo possibilitados pelo aparato audiovisual redimensionam a todo momento a percepção do que é presente, passado e futuro na diegese. Embora o que se mostre na tela, obviamente, refira-se sempre a algo passado, no momento em que assistimos ao filme atualizamos esse passado e vivemo-lo no presente como algo que nos acomete aqui e agora. Daí a carga dramática que ganha. As elipses temporais operadas pela montagem são explicitamente indicadas ao espectador através de letterings do tipo: "3 meses antes", "duas semanas depois".

Fora os enfermos, participam dos episódios familiares, amigos e profissionais de saúde. Cada um aparece falando sobre os temas que lhes são mais pertinentes. Os moribundos costumam discorrer sobre a descoberta da doença, o enfrentamento da morte, as recordações do passado, a forma como pretendem viver 0 tempo que lhes resta e os últimos desejos. Os médicos geralmente informam os prognósticos e as possibilidades de tratamento. As enfermeiras e cuidadores aparecem auxiliando os doentes, aliviando suas dores e apoiando-os psicologicamente na hora da morte a fim de tornar "a passagem" menos traumática. Os familiares falam sobre a importância que a pessoa doente tem em suas vidas, a dor da perda e o luto.

Além de entrevistas, o programa utiliza bastante fotografias e filmes de família com o objetivo de cobrir uma locução off e dar a conhecer a aparência da pessoa quando saudável. Registros do dia a dia buscam mostrar o cotidiano de cada um frente à doença. Há também uma série de imagens de paisagens que são utilizadas para fazer a transição entre sequências. Na maior parte das vezes essas imagens tem um tom bastante poético e vêm acompanhadas de trilha sonora.

\section{Time of death, um novo acontecimento discursivo na TV}

Numa sociedade em que a morte natural tem sido recalcada (FREUD, 2009), interditada (ARIÉS, 2012, 2014), empurrada para os bastidores da vida social (ELIAS, 2001) causa enorme estranheza ver o que no geral se quer esconder - a dor, o sofrimento, a decrepitude do corpo e a morte - sendo publicizado pelas câmeras de TV. Não que a morte seja algo raro na mídia televisiva, ao contrário, na contemporaneidade, ela tornou-se um acontecimento essencialmente televisual. Mas não é qualquer morte que ocupa a tela da TV. Prevalece nos telejornais a morte trágica, decorrente de terremotos, enchentes, deslizamentos, massacres, chacinas, atentados, assassinatos, acidentes etc. A morte natural de velhos e enfermos não ganha visibilidade nos telejornais. No geral, só são retratadas quando se trata de celebridades ou de doença rara.

Diferentemente do caráter acidental, fortuito e violento da morte abordada pela cobertura jornalística, na série do Showtime a morte não é vista como uma surpresa, um incidente. Quando a história de uma personagem é narrada 
em flashback, exibe-se logo de início seu corpo morto ou a cerimônia de seu sepultamento. Já quando a narrativa segue uma cronologia linear (da doença à morte), o próprio doente anuncia de imediato que lhe resta pouco tempo de vida. Nunca é construído um momento de suspense ou hesitação em torno da morte. De forma complementar, a transformação do corpo-doente em um corpo-cadáver se dá de maneira gradual, quase imperceptível, algo bem diferente do que ocorre nas narrativas ficcionais, que costumam representar a morte através da passagem bastante visível de um corpo animado a um estático (SOBCHAK, 2005). Time of death não hesita em mostrar o corpo morto. Tudo isso faz com que o programa destoe das gramáticas usuais sobre a morte e o morrer na TV. Daí o enorme estranhamento que causa.

Sobchack (2005) afirma que 0 ato da visão que torna possível a representação da morte está sujeito a um exame moral, pois, não se olha e filma a morte de um outro impunemente. A autora alega que os programas informativos e documentais quando quebram o tabu visual ao olhar para a morte precisam justificar sua transgressão cultural. Para tanto, devem tornar a própria transgressão visível, pois "a representação visível da visão inscreve 0 ver em sua dimensão moral" (2005, p.143). Segundo Sobchack, são os signos cinematográficos, historicamente codificados no movimento de estabilidade/instabilidade da câmera, enquadramento, distância que separa a câmera do acontecimento, persistência ou relutância do olhar, que permitem ao espectador julgar a conduta ética do cinegrafista diante da morte. Ainda de acordo com pesquisadora norte-americana, a justificação ética para a representação da morte exige que o sujeito da câmera indique não ter responsabilidade na morte que vê e dá a ver, bem como deixe claro que 0 ato de permanecer olhando/filmando não substitui uma possível intervenção no evento.

É o caso de Time of death, pois não há nada que possa ser feito em relação à morte das personagens em cena, todas estão com os dias contados. Além disso, os sujeitos autorizaram a equipe filmar seus últimos dias de vida. Nenhuma filmagem acontece sem 0 consentimento dos presentes. Na montagem final, Maria aparece falando porque permitiu uma câmera registrar sua doença e morte. A mãe da jovem Nicolle também revela porque a filha deixou-se ser filmada. As respostas convergem no sentido de desmitificar o tabu em relação à morte e da possibilidade de suas histórias servirem de ajuda a quem está passando por situação semelhante.

Sobchack propõe cinco formas de se olhar a morte dentro de princípios éticos ${ }^{9}$. Time of death inscreve-se na sua definição de "visão humanitária", posto que une o olhar do sujeito que filma ao olhar dos sujeitos filmados, transmitindo 
proximidade, respeito e simpatia por aqueles que morrem diante da câmera. Esse olhar humanitário é ainda reforçado pela forma como o programa discursiviza a ideia de "boa morte" dos CP, que justamente pretende humanizar o morrer e a morte.

\section{0 dizível e 0 visível dos cuidados paliativos em Time of death}

Embora seja impossível ver a morte, porque a passagem do ser para o não-ser não é visível, não é representável, Time of death busca mostrar 0 instante do passamento através de alguns recursos de linguagem. Por exemplo, nos casos em que 0 doente autorizou a equipe de filmagem acompanhar seus momentos finais, a câmera se mantém direcionada para ele, objetivando com a continuidade da tomada captar o momento exato em que os movimentos mínimos cessarão.

É verdade que a montagem atenua esse olhar intrusivo quando, a partir de cortes breves, sobrepõe à imagem do moribundo morrendo algumas outras. Trata-se de uma espécie de desvio do olhar diante de uma imagem incômoda. Incômoda por várias razões: porque nos obriga a presenciar a angústia da situação; porque já não mais reconhecemos naquele corpo desfigurado a pessoa de outrora - agora reduzida à sua condição de animalidade (boca aberta, cabeça levemente arqueada para trás e para cima, olhos fundos, pele pálida, ritmo da respiração acelerado e a falta de consciência); porque sabemos que um dia essa fisionomia será a nossa.
Figura 2: Michel.

Time of death (Showtime, 2013)

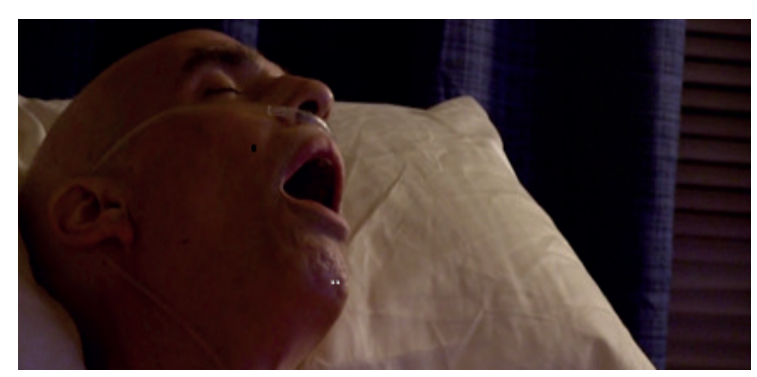

Figura 3: Nicolle.

Time of death (Showtime, 2013)

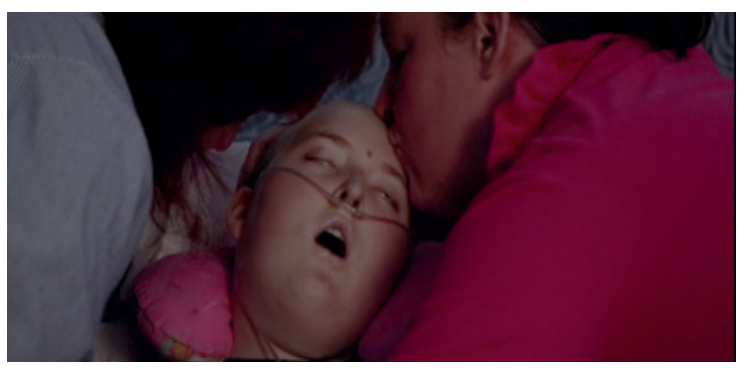

Figura 4: Laura.

Time of death (Showtime, 2013)

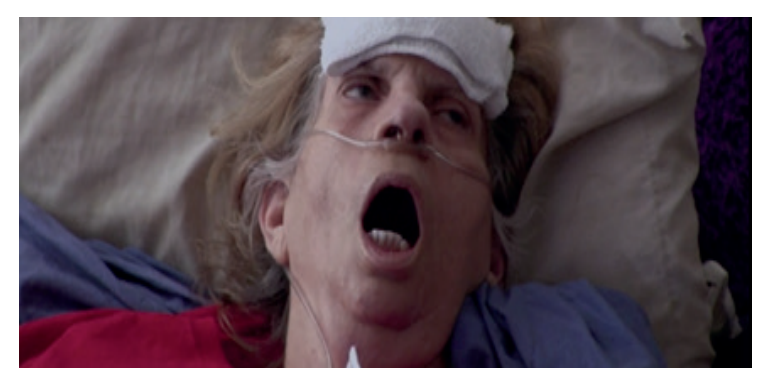

Um outro recurso utilizado para "dar a ver" a

morte é a inserção de um lettering anunciando a hora exata do falecimento de cada personagem.

Não é à toa que este é o nome da série, cujo

objetivo é dar visibilidade a esse tema. 0 programa nos lembra que a hora da morte, assim como a do nascimento, tem valor primordial para existência. 
Figura 5: Hora da morte de Nicolle. Time of death (Showtime, 2013)

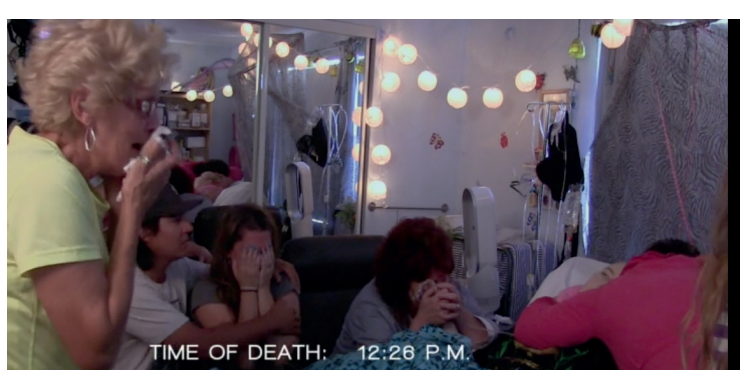

Registrar a hora da morte de cada personagem também funciona como estratégia de singularização. Se, por um lado, nascimento e morte são acontecimentos universais; por outro, ninguém pode nascer ou morrer no lugar do outro. Várias são as estratégias de construção da individualidade das personagens. Na montagem alternada, quando um lettering anuncia 0 nome da pessoa cuja vida será retratada na sequência está cumprindo tal função. A forma como são feitas as entrevistas também tem efeito singularizante, pois, ainda que a voz do entrevistador possa por vezes ser ouvida, apenas os entrevistados aparecem enquadrados em plano médio e primeiro plano. Tal recurso restringe 0 olhar do espectador, cujo foco de atenção passa a ser exclusivamente 0 sujeito que ocupa a tela.

Por sua vez, não obstante todos os doentes partilharem a eminência da morte, o programa não lhes imputa um tratamento uniformizante, reduzindo-os à categoria de "pacientes terminais". 0 foco não é a doença. Tanto é assim que 0 discurso médico, embora não seja negligenciado, não é prevalente. Cabe prioritariamente aos moribundos, seus familiares e amigos (e não a um corpo médico especializado) falar sobre o enfrentamento da doença. Essas pessoas discorrem sobre a forma como lidam, no presente, com a sentença de uma morte próxima, articulando 0 agora às memórias do passado e às perspectivas de um futuro encurtado. $0 \mathrm{~s}$ depoimentos de familiares e amigos bem como as imagens de arquivo estão lá para documentar a trajetória de vida de cada um. Todos carregam uma biografia própria.

Além de dar a conhecer esse passado, o programa enfatiza a forma como as personagens conduzem o tempo de vida que lhes resta, sendo essa conduta exatamente aquilo que pode servir de exemplo para os demais. Especialmente os personagens de mais idade incorporam a "autoridade do moribundo" (BENJAMIN, 1993), pois, o saber prático que transmitem toma a forma de um conselho que não consiste em intervir do exterior na vida do outro, mas de comunicar uma experiência de modo mais efetivo e integral.

É o caso de Lenore, uma psicanalista de 74 anos, que ao descobrir um câncer de pâncreas em estágio avançado decide não fazer quimioterapia e resolve reunir familiares e amigos para uma festa de despedida. Mesmo quando confessa ansiedade e medo frente à perspectiva da morte, Lenore mostra-se serena. Mais próximo do seu falecimento, ela afirma estar "pronta para morrer" porque já fez tudo o que precisava fazer na vida e agora "era hora de dizer adeus". 
Brad, um senhor de 77 anos também se apresenta resignado perante a sua morte. Outra personagem que se mantém sempre calma na frente das câmeras é Toni (55), acometida por um câncer de pulmão após anos trabalhando num programa de prevenção contra 0 câncer. As mortes de Lenore, Brad e Toni são retratadas de forma muito serena. Não se vê qualquer um deles agonizando. Contribui para a construção desta morte mais apaziguada 0 fato da câmera não estar presente nos seus momentos finais.

Imagens das fachadas das casas das personagens são frequentes, acentuando a importância do lar como lugar ideal da "boa morte" e funcionando como mais uma estratégia de individualização.

Figura 6: Casa de Lenore. Time of death (Showtime, 2013)

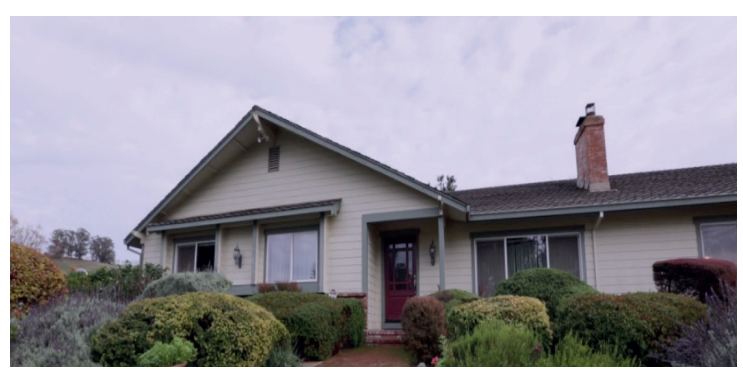

Figura 7: Casa de Toni. Time of death (Showtime, 2013)

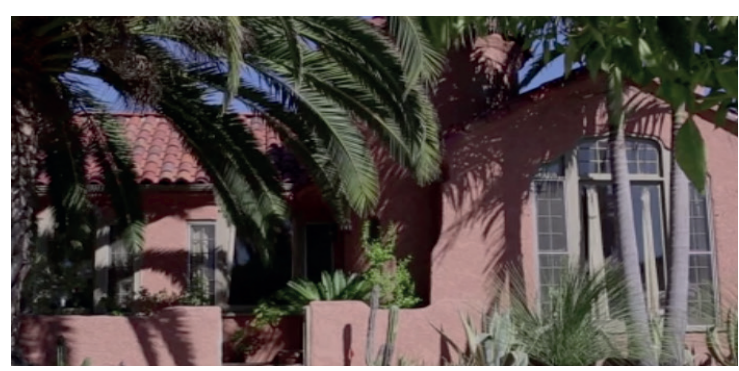

No geral, apesar da configuração da residência ter sido alterada pela presença de equipamentos hospitalares, médicos e cuidadores, impera nesse ambiente um clima de paz, harmonia e cuidado. Equipe médica, parentes e amigos mostram-se solícitos para atender os desejos do doente. Laura, por exemplo, é uma senhora cujo câncer está em metástase. Um de seus últimos desejos é viajar de carro com sua filha Lisa de Long Beach, Califórnia, para Colorado Springs. Laura costumava fazer essa viagem quando jovem, parando nos lugares turísticos. Sua doença se agrava durante a viagem e Lisa, a pedido da mãe, visita o Grand Canyon, sozinha. Laura morre na casa da irmã, após o Natal. Seu maior presente é ver Lisa e sua filha mais velha, Keri, reaproximando-se.

Cheyenne (47), vítima de ELA, já perdeu quase todos os movimentos do corpo. Comunica-se a partir de uma voz gerada por computador, ativada pelos seus movimentos oculares. Acredita que a doença é consequência de coisas ruins que fez no passado: aos 15 anos abandonou a mãe, quando o pai morreu; envolveu-se com drogas; cometeu um crime pelo qual foi para a cadeia; teve dois filhos com mulheres diferentes, os quais só veio a conhecer - e que só conheceram um ao outro - quando ele já estava doente. Apesar de tudo isso, ao final, sua vida parece estar redimida. Ele é cuidado por sua namorada e por uma equipe de CP, de quem recebe um tratamento afetuoso. Seus filhos e sua mãe também estão ao seu lado.

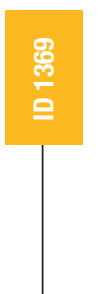


Michel (47) é outro que se considera um "bad boy" por ter se envolvido com drogas na juventude e dado muita preocupação aos pais, a quem pede desculpas. Ele manifesta o desejo de se reconciliar com sua primeira esposa, Andrea, com quem teve uma relação bastante conturbada, confessando ter batido nela. Um pouco antes de morrer, Andrea chega para visitá-lo. 0 desejo de reconciliação de Michel é, então, realizado.

A exceção de Maria, todas as personagens morrem ao lado dos familiares. A princípio, é de se estranhar que justo a protagonista do programa tenha uma morte tão solitária. É também Maria quem tem 0 final de vida mais conturbado.

Enquanto as demais personagens conseguem resolver seus problemas familiares e/ou realizar seus desejos antes da morte, a vida de Maria se complica a cada episódio, o seu câncer se agrava e problemas de outra natureza lhe atingem. Ela luta no tribunal para que a guarda de seus filhos mais novos não fique com o pai das crianças, mas com Nicole. Com receio de não ter tempo de resolver essa situação antes de morrer, ela resolve iniciar nova quimioterapia bem como participar como voluntária de pesquisas com medicamentos ainda em teste. A medicação altera seu estado de consciência e humor. Ela e os filhos têm muita dificuldade de lidar com todas essas circunstâncias. Sua relação com Julia e Andrew se fragiliza a ponto de ela interná-los numa instituição para adolescentes. Maria morre sem ter resolvido suas pendências afetivas e jurídicas.
A cremação de Maria ocorre sem maiores preparativos. Quando seu corpo adentra a câmera de incineração abrigado numa espécie de caixa de papelão, percebe-se que está vestido com a mesma roupa da hora de sua morte. Estão presentes apenas o seu pai e Nicole, acompanhada de uma amiga. Trata-se bem mais de um acontecimento protocolar do que de uma cerimônia de despedida. Só posteriormente familiares e amigos se reúnem para lhe prestar homenagem.

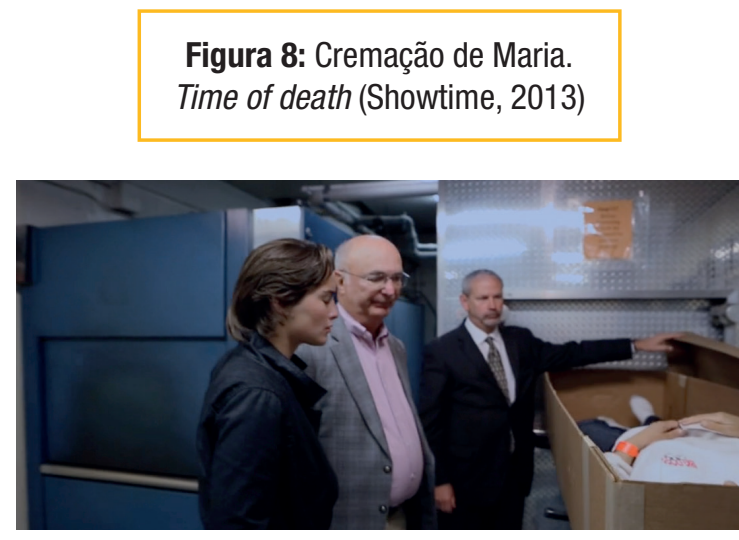

Esse tratamento destoa bastante daquele dado às demais personagens, alvo de muitos cuidados postmortem. Por exemplo, os corpos são vestidos com roupas e adereços especiais para ocasião e os funerais são pomposos, com a presença de muitos amigos.

Figura 9: Cheynne.

Time of death (Showtime, 2013)

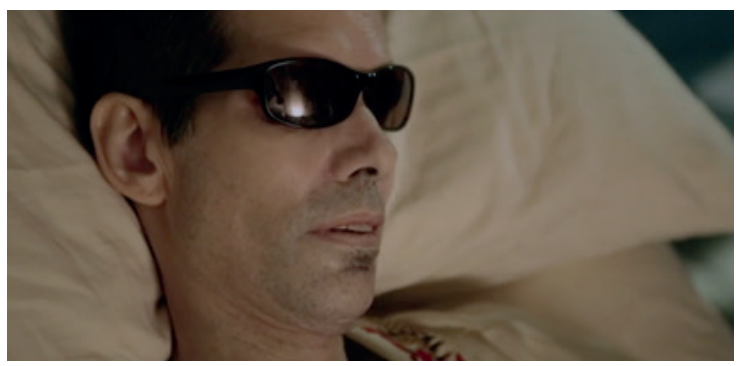



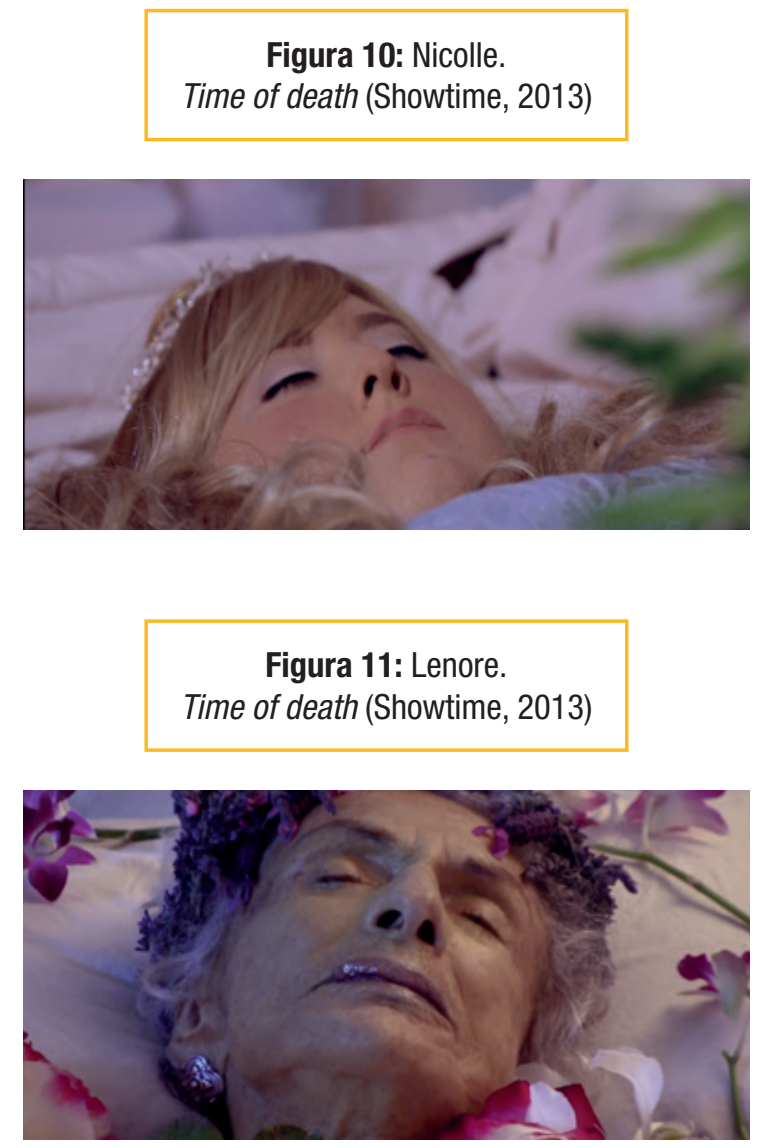

0 estranhamento inicial com a representação sofrida do processo de morrer e da morte de Maria se desfaz quando percebemos que ela é a personagem que menos segue os procedimentos dos CP. Ela sempre aparece realizando exames e consultas em hospitais e clínicas tradicionais. Especialmente quando opta por tratamentos que podem lhe dar uma sobrevida, mas lhe custam qualidade de vida, ela se coloca na contramão dos ideários paliativistas ${ }^{10}$.

0 fim melancólico desta personagem (que morre solitária em casa sem ter resolvidos seus problemas e realizado seus desejos), em contraste com a morte redentora das demais, sugere que há formas melhores e piores de morrer, sendo a mais adequada aquela construída em torno dos ideários paliativistas. É possível contra argumentar dizendo que o programa não construiu o ethos de Maria como sofredora deliberadamente, pois, como se trata de uma personagem real, ele não poderia controlar o curso de sua vida e morte. É verdade, mas apenas em parte. Primeiro, porque manter a história de Maria no programa é uma escolha. Rigorosamente, ela não precisaria estar no corte final. No entanto, não simplesmente está, como é protagonista da série. Segundo, ao exibir mortes mais suaves, a montagem termina relegando à Maria uma morte menos digna. Não se pode negar que este fato é atenuado no episódio final quando o espectador testemunha que o maior desejo de Maria foi finalmente realizado: Julia e Andrew agora estão sob a tutela da Nicole.

Para não transparecer totalitário, o programa por vezes deixa vazar um discurso outro, indicando que os princípios dos CP não são infalíveis. Por exemplo, logo após a morte de sua mãe, Lisa dá um depoimento bastante choroso em que revela: "Ninguém está preparado para ver o outro morrer, é apavorante, é feio e dói ver". Assim, ela se contrapõe à ideia da cena pacífica e tranquila da morte dos CP. Também a jovem Nicolle (19), em lágrimas, confessa ao pai: "não estou preparada para morrer", manifestando a dificuldade de aceitar 0 seu destino. 
Ainda é importante assinalar que ao acompanhar apenas o período de vida final dos moribundos, Time of death deixa de fora os prováveis conflitos anteriores dos doentes com relação à aceitação da doença, incluindo uma possível vitimização de si. Muitos distantes do ethos da vítima, os personagens são subjetivados como verdadeiros heróis que enfrentam corajosamente a angústia de uma morte próxima e certa, mas em aberto.

Contribui para esta construção o fato do programa, ao narrar histórias reais de vida, adotar o modelo da "jornada do herói" (CAMPBELL, 1997; VOGLER, 2009), típico da ficção. A narrativa de cada personagem segue uma curva dramática em que, com a revelação da proximidade da morte, os protagonistas são tirados de seu "mundo comum" e chamados à aventura: 0 combate à doença. E mesmo a morte não implica um fracasso, porque agora eles podem seguir sua jornada em um "outro mundo". No caso de Maria, 0 efeito de ficcionalização é ainda maior, porque como sua história é contada de forma segmentada, o programa pode, entre um episódio e outro, dosar a carga dramática dos eventos. A "novelização" de sua história serve como gancho para que 0 espectador queira acompanhar o desenlace dos acontecimentos, tornando-se fiel ao programa.

É também fácil reconhecer em Time of death a figura da "bela morte" personificada pelo herói grego que luta e morre no campo de batalha (VERMANT, 1978), bem como a morte romântica (ÁRIES, 2012). Um exemplo do primeiro tipo é o momento em que os filhos de Maria cortam o cabelo da mãe antes do início de sua quimioterapia, numa espécie de ritual preparatório para a batalha. Já uma cena típica da morte romântica acontece quando Ruth, após toda uma noite de vigília, acolhe em seus braços o namorado Cheyenne. Esses modelos simbólicos da morte, tornam as imagens do morrer e da morte mais suportáveis.

Figura 12: 0s filhos cortam o cabelo Maria antes da quimioterapia. Time of death (Showtime, 2013)

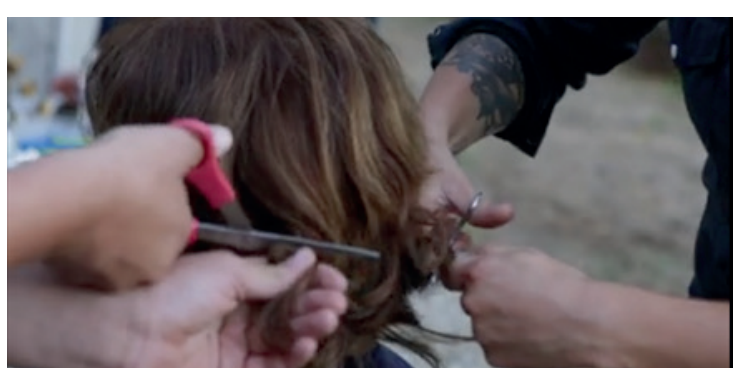

Figura 13: Ruth faz vigília ao lado da cama de Cheynne. Time of death (Showtime, 2013)

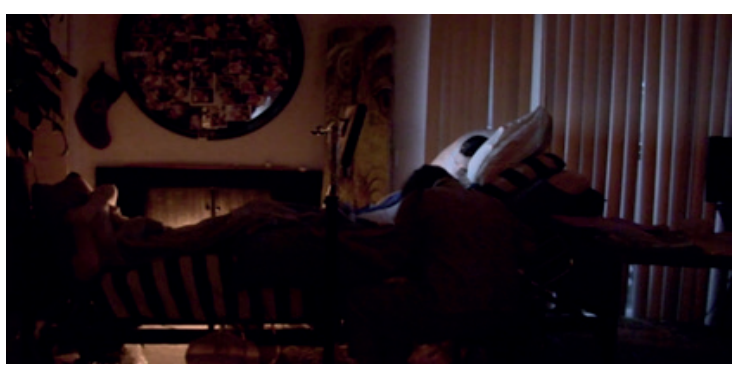

\section{Considerações finais}

De acordo com os ideais dos CP, o processo de morrer deve ser vivido na intimidade. No caso de Time of death, espécie de peça de propaganda

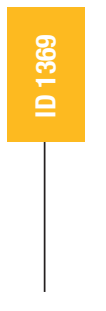


audiovisual dos ideários paliativistas, resta indagar de que intimidade se trata, pois, no contexto de um programa de TV, o ideal de uma morte mais recatada e intimista passa a ser um produto consumido e consumível por um vasto público. Mesmo o olhar humanista que o programa imprime ao moribundo não anula esse aspecto.

Em Time of death os procedimentos de humanização objetivam permitir que se olhe a morte do outro sem que princípios éticos sejam violados. Como a série enfoca a morte de doentes terminais, para os quais a morte é certa e próxima, o espectador está liberado para olhar sem culpa. Além disso, os próprios moribundos querem ser alvo do olhar alheio para que suas experiências de doença e morte sirvam para recolocar em discurso o processo do morrer.

Nesse contexto, Time of death opera como uma máquina de governo que faz ver e faz falar os moribundos. No conjunto, a fala e a imagem dos enfermos sugere que há um "jeito certo de morrer", justo aquele dos CP. Mesmo não se assumindo explicitamente como uma peça institucional, o programa sustenta e divulga 0 discurso paliativista. E o faz a partir de uma estratégia bastante sedutora porque na tela tudo acaba bem para aquele que opta por morrer no aconchego do lar, sendo cuidado afetuosamente por uma equipe de saúde especializada, recebendo amor e carinho das pessoas amadas e ainda podendo realizar os seus desejos derradeiros. Quem não ficaria fascinado pelo imaginário redentor da boa morte?
0 fato de Time of death ser um reality show permite ainda misturar procedimentos típicos do registro documental a estratégias ficcionalizantes. Nesse sentido, recuperam-se figuras e cenas históricas da morte capazes de atrair o público e atuar na espetacularização do acontecimento, como a luta e a morte do herói no campo de batalha, a morte nos braços da amada, as palavras finais pronunciadas para a comunidade. Tais recursos facilitam a identificação do público com a personagem em via de morrer. Em outro contexto, dificilmente alguém se identificaria com uma personagem que vai morrer, mas já que a morte é certa, melhor que seja uma "boa morte".

Enfim, os procedimentos narrativos de Time of death são elaborados de forma, por um lado, a acentuar o caráter humanista e redentor dos CP (testemunhos de vida, material de arquivo, cenas de afeto dos doentes ao lado de parentes e amigos, etc.) e, por outro, a amenizar aspectos considerados difíceis de visualizar com relação ao processo de morrer e a morte (a ausência de cenas de dor e sofrimento).

Por fim, vale assinalar que 0 discurso de aceitação da morte dos $\mathrm{CP}$ contrasta com 0 desejo de administrá-la. Trata-se ainda do ethos individualista do sujeito neoliberal, levado a pensar a si mesmo como alguém que modela ativamente 0 curso de sua vida (e de sua morte) através de atos de escolha. 


\section{Referências}

ACADEMIA NACIONAL DE CUIDADOS PALIATIVOS.

Manual de Cuidados Paliativos. ANCP. 2 ${ }^{\mathrm{a}}$. ed. 2012.

ARIÈS, Philippe. História da morte no 0cidente. São

Paulo: Editora Saraiva, 2012.

. 0 homem diante da morte. $1^{\mathrm{a}} \mathrm{ed}$.

São Paulo: Editora Unesp, 2014.

BENJAMIN, Walter. 0 narrador, considerações sobre a

obra de Nikolai Leskov. In: Obras Escolhidas, Magia

e Técnica, Arte e Política. 5 ${ }^{\mathrm{a}}$. Ed. São Paulo: Editora

Brasiliense, 1993.

BIFULCO, Vera Anita; CAPONERO, Ricardo. Cuidados paliativos: conversas sobre a vida e a morte na saúde. Barueri, SP: Minha Editora, 2016.

CAMPBELL, Joseph. 0 herói de mil faces. São Paulo: Cultrix-Pensamento, 1997.

FOUCAULT, Michel. Vigiar e Punir. Petrópolis, RJ:

Vozes, 1987.

História da sexualidade, vol.1, A

vontade de saber. Rio de janeiro: Graal, 1997.

Microfísica do poder. Rio de janeiro:

Graal, 2000.

FREUD, Sigmund. Escritos sobre a guerra e a morte.

Portugal, Covilhã: LusoSofia Press, 2009.

KÜBLER-ROSS, Elisabeth. Sobre a morte e o

morrer: o que os doentes terminais têm a ensinar

a médicos, enfermeiras, religiosos e aos seus

próprios parentes. $9^{\mathrm{a}}$. ed. São Paulo: Editora WMF

Martins Fontes, 2008.

MENEZES, Rachel Aisengart. Em busca da boa

morte. Antropologia dos cuidados paliativos. Rio de

Janeiro: Garamond, Fiocruz, 2004.

NOBERT, Elias. A solidão dos moribundos. Rio de Janeiro (RJ): Jorge Zahar, 2001.
ROSE, Nikolas. A política da própria vida.

Biomedicina, poder e subjetivação no século XXI.

São Paulo: Paulus, 2013.

SOABCHACK, Vivian. Inscrevendo o espaço ético: dez proposições sobre morte, representação e documentário. In: Teoria contemporânea do cinema - Documentário e narratividade ficcional. vol. II. 2005, p.127 a 157.

SUDOW, David. Passing on. The social organization of dyin. New Jersey: Prentice-Hall, 1967.

VERMANT, Jean-Pierre. A bela morte e 0 cadáver ultrajado. In: Discurso, $n^{0}$ 9, 1978.

VOGLER, Christopher. A jornada do escritor, estruturas míticas para escritores. $2^{\mathrm{a}}$. Ed. Rio de Janeiro: Nova Fronteira: Sinergia: Ediouro, 2009.

Programa de TV: Time of death. Showtime. 2013. 


\section{A new government} of death on TV

\section{Un nuevo régimen de la muerte en la television}

\section{Abstract}

We are living a cultural change in which new ways of dying emerge for the subjects. Palliative Care is one of these new death regimes. We argue that, while standing against a biopolitics of investing in life at any cost, Palliative Care are in line with contemporary governmentalism in which optimization of life prevails. The ethos of the dying is the same as the neoliberal individual, led to think of himself as someone who actively models the course of his life (and his death) through acts of choice. To show how this happens, we chose as object of analysis an American TV series that is based on the precepts of the palliative care called Time of death (2013).

\section{Keywords}

Time of death; Palliative Care; biopolitics; governmentalism, ethos neoliberal.

\section{Resumen}

Estamos frente a un cambio cultural en el que nuevas formas de morir emergen para los sujetos. Los Cuidados Paliativos son uno de estos nuevos esquemas de la muerte. Sostenemos que, a pesar de que se ponen contra la inversión biopolítica en la vida a cualquier precio, el CP están en línea con la gubernamentalidad contemporáneo en el que reina una optimización de la vida. El ethos agonizante es el mismo de lo individuo neoliberal, hizo pensar a sí mismo como alguien que configura activamente el curso de su vida (y de su muerte) a través de los actos de elección. Para mostrar cómo sucede esto, hemos elegido como objeto de análisis una serie de televisión estadounidense que se basa en los preceptos de la CP llamada Time of death (2013).

\section{Palabras clave}

Time of death; Cuidados Paliativos; biopolítica, gubernamentalidad, ethos neoliberal. 


\section{Expediente}

A revista E-Compós é a publicação científica em formato eletrônico da Associação Nacional dos Programas de Pós-Graduação em Comunicação (Compós). Lançada em 2004, tem como principal finalidade difundir a produção acadêmica de pesquisadores da área de Comunicação, inseridos em instituições do Brasil e do exterior.

\section{E-COMPÓS I www.e-compos.org.br I E-ISSN 1808-2599}

Revista da Associação Nacional dos Programas de Pós-Graduação em Comunicação. Brasília, v.20, n.3, set./dez. 2017. A identificação das edições, a partir de 2008 , passa a ser volume anual com três números. Indexada por Latindex I www.latindex.unam.mx

\section{CONSELHO EDITORIAL}

Ada Cristina Machado Silveira, Universidade Federal de Santa Maria, Brasil Alda Cristina Silva da Costa, Universidade Federal do Pará, Brasil Alfredo Luiz Paes de Oliveira Suppia, Universidade Estadual de Campinas, Brasil Ana Regina Barros Rego Leal, Universidade Federal do Piauí, Brasil Ana Carolina Rocha Pessôa Temer, Universidade Federal de Goiás, Brasil André Luiz Martins Lemos, Universidade Federal da Bahia, Brasil Angela Cristina Salgueiro Marques, Universidade Federal de Minas Gerais, Brasil Ângela Freire Prysthon, Universidade Federal de Pernambuco, Brasil Antonio Carlos Hohlfeldt, Pontifícia Universidade Católica do Rio Grande do Sul, Brasil Arthur Ituassu, Pontifícia Universidade Católica do Rio de Janeiro, Brasil

Bruno Campanella, Universidade Federal Fluminense, Brasil

Cláudio Novaes Pinto Coelho, Faculdade Cásper Líbero, Brasil Cárlida Emerim, Universidade Federal de Santa Catarina, Brasil Carlos Eduardo Franciscato, Universidade Federal de Sergipe, Brasil Danilo Rothberg, Universidade Estadual Paulista, Brasil Denise Tavares da Silva, Universidade Federal Fluminense, Brasil Diógenes Lycarião, Universidade Federal do Ceará, Brasil Eduardo Vicente, Universidade de São Paulo, Brasil Eliza Bachega Casadei, Escola Superior de Propaganda e Marketing - SP, Brasil Eneus Trindade, Universidade de São Paulo, Brasil

Erick Felinto de Oliveira, Universidade do Estado do Rio de Janeiro, Brasil Erly Vieira Júnior, Universidade Federal do Espírito Santo, Brasil Francisco de Assis, FIAM-FAAM Centro Universitário, Brasi

Francisco Elinaldo Teixeira, Universidade Estadual de Campinas, Brasil Francisco Gilson R. Pôrto Jr., Universidade Federal do Tocantins, Brasil Frederico de Mello Brandão Tavares, Universidade Federal de Ouro Preto, Brasil Gabriela Reinaldo, Universidade Federal do Ceará, Brasil Gilson Vieira Monteiro, Universidade Federal do Amazonas, Brasil Gustavo Daudt Fischer, Universidade do Vale do Rio dos Sinos, Brasil Itania Maria Mota Gomes, Universidade Federal da Bahia, Brasil Jiani Adriana Bonin, Universidade do Vale do Rio dos Sinos, Brasil José Afonso da Silva Junior, Universidade Federal de Pernambuco, Brasil José Luiz Aidar Prado, Pontifícia Universidade Católica de São Paulo, Brasi Josette Maria Monzani, Universidade Federal de São Carlos, Brasi Juçara Gorski Brittes, Universidade Federal de Ouro Preto, Brasil
Juliana Freire Gutmann, Universidade Federal da Bahia, Brasil Laura Loguercio Cánepa, Universidade Anhembi Morumbi, Brasil Leonel Azevedo de Aguiar, Pontifícia Universidade Católica do Rio de Janeiro, Brasil Letícia Cantarela Matheus, Universidade do Estado do Rio de Janeiro, Brasil Luciana Coutinho Souza, Universidade de Sorocaba, Brasil Maria Ataide Malcher, Universidade Federal do Pará, Brasil Maria Elisabete Antonioli, Escola Superior de Propaganda e Marketing - SP, Brasil Maria das Graças Pinto Coelho, Universidade Federal do Rio Grande do Norte, Brasil Marialva Carlos Barbosa, Universidade Federal do Rio de Janeiro, Brasil Marcel Vieira Barreto Silva, Universidade Federal da Paraíba, Brasil Marcia Tondato, Escola Superior de Propaganda e Marketing, Brasil Marli Santos, Universidade Metodista de São Paulo, Brasil

Márcio Souza Gonçalves, Universidade do Estado do Rio de Janeiro, Brasil Mauricio Mario Monteiro, Universidade Anhembi Morumbi, Brasil Mayka Castellano, Universidade Federal Fluminense, Brasil

Mozahir Salomão Bruck, Pontifícia Universidade Católica de Minas Gerais, Brasil Nisia Martins Rosario, Universidade Federal do Rio Grande do Sul, Brasil Paolo Demuru, Universidade Paulista, Brasil

Paula Melani Rocha, Universidade Estadual de Ponta Grossa, Brasil Potiguara Mendes Silveira Jr, Universidade Federal de Juiz de Fora, Brasil Priscila Ferreira Perazzo, Universidade Municipal de São Caetano do Sul, Brasil Rafael Cardoso Sampaio, Universidade Federal do Paraná, Brasil Rafael Tassi Teixeira, Universidade Tuiuti do Paraná, Brasil Regiane Lucas Garcês, Universidade Federal de Minas Gerais, Brasil Regiane Regina Ribeiro, Universidade Federal do Paraná, Brasil Renata Pitombo Cidreira, Universidade Federal do Recôncavo da Bahia, Brasil Renato Essenfelder, Escola Superior de Propaganda e Marketing, Brasil Roberto Elísio dos Santos, Universidade Municipal de São Caetano do Sul, Brasil Rodolfo Rorato Londero, Universidade Estadual de Londrina, Brasil Roseli Figaro, Universidade de São Paulo, Brasil

Simone Maria Andrade Pereira de Sá, Universidade Federal Fluminense, Brasil Sofia Cavalcanti Zanforlin, Universidade Católica de Brasília, Brasil Sônia Caldas Pessoa, Universidade Federal de Minas Gerais, Brasil Tatiana Oliveira Siciliano, Pontifícia Universidade Católica do Rio de Janeiro, Brasil Thaïs de Mendonça Jorge, Universidade de Brasília, Brasil

Valquiria Michela John, Universidade Federal do Paraná, Brasil

\section{CONSELHO CIENTÍFICO}

Cristiane Freitas Gutfreind, Pontifícia Universidade Católica do Rio Grande do Sul, Brasil | Eduardo Antônio de Jesus, Universidade Federal de Minhas Gerais, Brasil I Eduardo Morettin, Universidade de São Paulo, Brasil I Irene de Araújo Machado, Universidade de São Paulo, Brasil I Miriam de Souza Rossini, Universidade Federal do Rio Grande do Sul, Brasil

\section{COMISSÃO EDITORIAL}

Eduardo Antonio de Jesus, Universidade Federal de Minas Gerais, Brasil I Igor Pinto Sacramento, Universidade Federal do Rio de Janeiro, Brasil I Kelly Cristina de Souza Prudencio, Universidade Federal do Paraná, Brasil I Osmar Gonçalves dos Reis Filho, Universidade Federal do Ceará, Brasil I Rafael Grohmann, FIAMFAAM - Centro Universitário, Brasil (editor associado)

\section{CONSULTORES AD HOC}

Afonso de Albuquerque, Universidade Federal Fluminense, Brasil I Francisco Rüdiger, Pontifícia Universidade Católica do Rio Grande do Sul, Brasil I Gislene da Silva, Universidade Federal de Santa Cataria, Brasil I Luiz Cláudio Martino Universidade de Brasília, Brasil I Magali Nascimento Cunha, Universidade Metodista de São Paulo, Brasil I Márcia Franz Amaral, Universidade Federal de Santa Maria, Brasil I Tania Marcia Cezar Hoff, Escola Superior de Propaganda e Marketing, Brasil I Raquel Paiva, Universidade Federal do Rio de Janeiro, Brasil

\section{EQUIPE TÉCNICA}

ASSISTENTE EDITORIAL Márcio Zanetti Negrini I REVISÃO DE TEXTOS Melina Santos I EDITORAÇÃO ELETRÔNICA Roka Estúdio
COMPÓS I www.compos.org.br

Associação Nacional dos Programas de Pós-Graduação em Comunicação

Presidente

Marco Roxo

Programa de Pós-Graduação em Comunicação - UFF marcos-roxo@uol.com.br

Vice-Presidente

Isaltina Gomes

Programa de Pós-Graduação em Comunicação - UFPE isaltina@gmail.com

Secretária-Geral

Gisela Castro

Programa de Pós-Graduação em Comunicação

e Práticas de Consumo - ESPM

castro.gisela@gmail.com

CONTATO I revistaecompos@gmail.com 